\section{Fragment Size Difference between Multiplex and Singleplex PCR Products and Their Practical Implications}

BioTechniques 29:298-308 (August 2000)

\begin{abstract}
By simultaneously amplifying several loci in the same reaction, multiplex PCR has been used in gene mapping and DNA typing with polymorphic short tandem repeat loci. Previous studies have discussed in detail the various parameters and conditions that influence the quantity of individual products generated by multiplex PCR. In practice, when a primer pair fails to amplify in a multiplex PCR for some individuals, singleplex PCR is often employed as a supplement to amplify the primer pair. However, the reliability of this procedure is unknown. In this study, we used six primer pairs from ABI PRISM ${ }^{\mathrm{TM}}$ Linkage Mapping Set version 2 to perform multiplex and singleplex reactions. The fluorescence-labeled amplification products were separated and detected on ABI PRISM 310 Genetic Analyzer. We found that for the marker D1S468, multiplex and singleplex reactions for the majority of individuals yielded reactions of different sizes. Therefore, the potential size difference between multiplex and singleplex reactions needs to be investigated. This investigation is essential to employ multiplex PCR supplemented with singleplex PCR in gene mapping and DNA typing.
\end{abstract}

\section{INTRODUCTION}

Multiplex PCR was first proposed by Chamberlain et al. (4), in which two or more loci are simultaneously amplified in the same reaction (9). When more than one primer pair per reaction is used, the total number of reactions in an experiment is reduced. This procedure conserves expensive reagents and DNA samples and decreases potential contamination (3); therefore, it has been used in situations when many reactions are involved, such as DNA typing and gene mapping with polymorphic short tandem repeat (STR) loci $(7,11,16,18)$. Previous studies have focused on the role of various reagents in optimizing multiplex PCR protocols $(9,12,13,17)$. Primer-primer interaction has been one major subject studied for multiplex PCR (9). In primer-primer interaction, various primers and PCR products may compete for limited supplies of reagents and DNA samples, resulting in differential amplification of different loci $(9,17)$, or primers from the same or different loci may form primer dimers that reduce PCR product yield.

Multiplex PCR is more economical and efficient, but it may fail to amplify some loci for some individuals (11). It is a common practice to perform singleplex PCR (single-locus PCR) as a supplement to amplify those loci in individuals for whom the multiplex PCR fails to amplify (11). However, little attention has been paid to the consistency of products between multiplex and singleplex reactions.

The ABI PRISM ${ }^{\mathrm{TM}}$ Linkage Mapping Set Version 2 (PE Biosystems, Foster City, CA, USA) uses new reverse primer-tailing chemistry to improve allele-calling efficiency by eliminating problems associated with non-template nucleotide addition (so-called "plus A"), which results in a higher fidelity and facilitates high-throughput genotyping (2,22). Recently, PE Biosystems recommended multiplex PCR amplification using the company's Linkage Mapping Set version 2 and AmpliTaq Gold ${ }^{\circledR}$ DNA polymerase (http://www. pebio.com/ab/apply/dr/dra1a5.html). In this study, we employed six markers from the linkage mapping set to perform multiplex and singleplex reactions and compared the fragment sizes of the resultant PCR products.

\section{MATERIALS AND METHODS}

\section{Subjects and Preparation of DNA Samples}

One CEPH 1347-02 DNA obtained from PE Biosystems was used with six DNA samples (denoted as c1-c6) obtained from the technicians in the laboratory. The other DNA samples (denoted as p1-p96) came from the subjects of a large human genetic study to characterize genetic determination (5) and to search for genes underlying the variation of human bone mineral density.

Blood $(20 \mathrm{~mL})$ of subjects was drawn by a certified phlebotomist into EDTA-containing tubes and was stored refrigerated until DNA extraction. The extraction was conducted with a kit (Gentra Systems, Minneapolis, MN, USA), according to the manufacturer's directions (11) and quantitated by a DU $^{\circledR}-64$ spectrophotometer (Beckman Coulter, Fullerton, CA, USA).

\section{PCR Conditions}

Singleplex reactions were carried out using $100 \mathrm{ng}$ genomic DNA. Fifteen-microliter reaction volumes contained $2.5 \mathrm{mM} \mathrm{MgCl} 2,1 \times \mathrm{GeneAmp}^{\circledR}$ PCR Buffer II; $250 \mu \mathrm{M}$ each dNTP (dATP, dCTP, dGTP and dTTP); 0.33 $\mu \mathrm{M}$ each forward and reverse primers and 0.6 U AmpliTaq Gold DNA polymerase. Unless otherwise specified, all reagents employed in this study were obtained from PE Biosystems. The $\mathrm{MgCl}_{2}$ concentration used in the singleplex PCR is recommended by the company for amplification with AmpliTaq Gold DNA polymerase (20).

Multiplex reactions were carried out using $200 \mathrm{ng}$ genomic DNA. The $50-\mu \mathrm{L}$ reaction volumes contained $2.5 \mathrm{mM}$

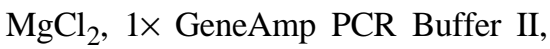
$250 \mu \mathrm{M}$ each dNTP, $0.17 \mu \mathrm{M}$ each forward and reverse primers and $5 \mathrm{U}$ AmpliTaq Gold DNA polymerase. Although PE Biosystems recommends multiplex PCR amplification using the Linkage Mapping Set and AmpliTaq Gold DNA polymerase (http://www.pebio.com/ab/ apply/dr/dra1a5.html), the multiplex condition is currently not available from the company. The $\mathrm{MgCl}_{2}$ concentration used in this study is the same as that from a study of multiplex PCR to a genetic linkage (11).

\section{Dinucleotide Repeat Markers}

Fluorescently labeled (Fam, Hex or Ned) forward primers of human dinucleotide repeat $(\mathrm{AC} / \mathrm{GT})_{\mathrm{n}}$ markers were from the linkage mapping set mentioned earlier. Table 1 shows the six markers from Panels 1 and 2 used in this study. 
Table 1. Dinucleotide Repeat Markers Employed

\begin{tabular}{|c|c|c|c|}
\hline Locus & Dye Label & Panel & Allele Size Range \\
\hline D1S213 & [NED] & 1 & $107-133$ \\
\hline D1S238 & [FAM] & 2 & $296-330$ \\
\hline D1S2667 & {$[\mathrm{HEX}]$} & 1 & $128-156$ \\
\hline D1S2726 & [NED] & 1 & $284-296$ \\
\hline D1S468 & {$[\mathrm{HEX}]$} & 2 & $193-213$ \\
\hline D1S484 & [HEX] & 1 & $276-290$ \\
\hline \multicolumn{4}{|c|}{$\begin{array}{l}\text { The data for this table were obtained from: http://www.pebio.com/ab/apply/dr/ } \\
\text { Imsv2/chrom1.html. The allele size range denotes the nucleotide range that is } \\
\text { obtained from the model } 377 \text { ABI PRISM DNA sequencer. The sequences of the } \\
\text { primers D1S484 and D1S468 employed here are proprietary (PE Biostystems) } \\
\text { and are not available. These sequences may be different from those found in the } \\
\text { reference (8). }\end{array}$} \\
\hline
\end{tabular}

\section{PCR Thermal Cycling Conditions}

The two PCR protocols used thermal cyclers (model 9700; PE Biosystems). For singleplex PCR, the thermal cycling conditions were $95^{\circ} \mathrm{C}$ for 12 min followed by 10 cycles of $94^{\circ} \mathrm{C}$ for $15 \mathrm{~s}, 55^{\circ} \mathrm{C}$ for $15 \mathrm{~s}$ and $72^{\circ} \mathrm{C}$ for $30 \mathrm{~s}$, followed by an additional 20 cycles of $89^{\circ} \mathrm{C}$ for $15 \mathrm{~s}, 55^{\circ} \mathrm{C}$ for $15 \mathrm{~s}$ and $72^{\circ} \mathrm{C}$ for $30 \mathrm{~s}$, followed by a final extension at $72^{\circ} \mathrm{C}$ for $10 \mathrm{~min}$, a protocol recommended by the manufacturer. For multiplex PCR, the thermal cycling conditions were $95^{\circ} \mathrm{C}$ for $5 \mathrm{~min}$ followed by 35 cycles of $94^{\circ} \mathrm{C}$ for $1 \mathrm{~min}, 60^{\circ} \mathrm{C}$ for 1 min and $72^{\circ} \mathrm{C}$ for $1 \mathrm{~min}$, followed by a final extension at $60^{\circ} \mathrm{C}$ for $30 \mathrm{~min}(11)$.

\section{Analysis of PCR Products}

The singleplex PCR products labeled with Fam and Hex were diluted 1:20, and the products labeled with Ned were diluted 1:15. The multiplex PCR products were all diluted 1:10. One microliter of each product was mixed with 12 $\mu \mathrm{L}$ formamide and $0.2 \mu \mathrm{L}$ internal size standard GS-500 Rox (PE Biosystems). The size standard contains DNA fragments fluorescently labeled with the dye Tamra (red) ranging in size from $50-500$ bp. After heat denaturation at $95^{\circ} \mathrm{C}$ for 5 min, the tubes were chilled on ice until the samples were loaded. Electrophoresis was performed using module GS STR POP4D (PE Biosystems), and the data were collected on a model $310 \mathrm{ABI}$ PRISM genetic analyzer. Fluorescently labeled DNA fragments were analyzed using GeneScan analysis software version 3.1. Allele size data were generated using Genotyper ${ }^{\circledR}$ 2.0 DNA fragment analysis software (all products were from PE Biosystems).

\section{RESULTS AND DISCUSSION}

Three Hex-labeled markers, D1S2667, D1S468 and D1S484, were combined to perform multiplex PCR (a 3-marker set) using DNA from CEPH 1347-02 and 15 random study subjects (p1-p15). Singleplex reactions were also conducted for each of these markers for the same DNA sample. Multiplex and singleplex PCR products were then analyzed on the same run on the genetic analyzer. We found that for the marker D1S468, the fragment sizes of the products obtained from multiplex PCR were all approximately 2 bp larger than those obtained from singleplex PCR (Figure 1). The difference in the fragment sizes between multiplex and singleplex reactions obtained in these 16 samples is between 1.67 and 2.07 $\mathrm{bp}$, with a mean of $1.87 \mathrm{bp}$ and SD of $0.09 \mathrm{bp}$. It appears that the multiplex PCR condition resulted in an addition of $2 \mathrm{bp}$ to the PCR product compared to the singleplex PCR, a phenomenon we termed a 2-bp shift. Throughout this 


\section{Short Technical Reports}

study, we define the 2-bp shift as a difference between the fragment lengths of multiplex and singleplex reactions greater than $1.6 \mathrm{bp}$ but less than $2.4 \mathrm{bp}$. With the 2-bp shift, the fragment size of each allele (one for homozygotes and two for heterozygotes) of an individual is increased by approximately $2 \mathrm{bp}$. For the other two markers, the fragment sizes matched very well for the multiplex and singleplex reactions.

According to fragment length and

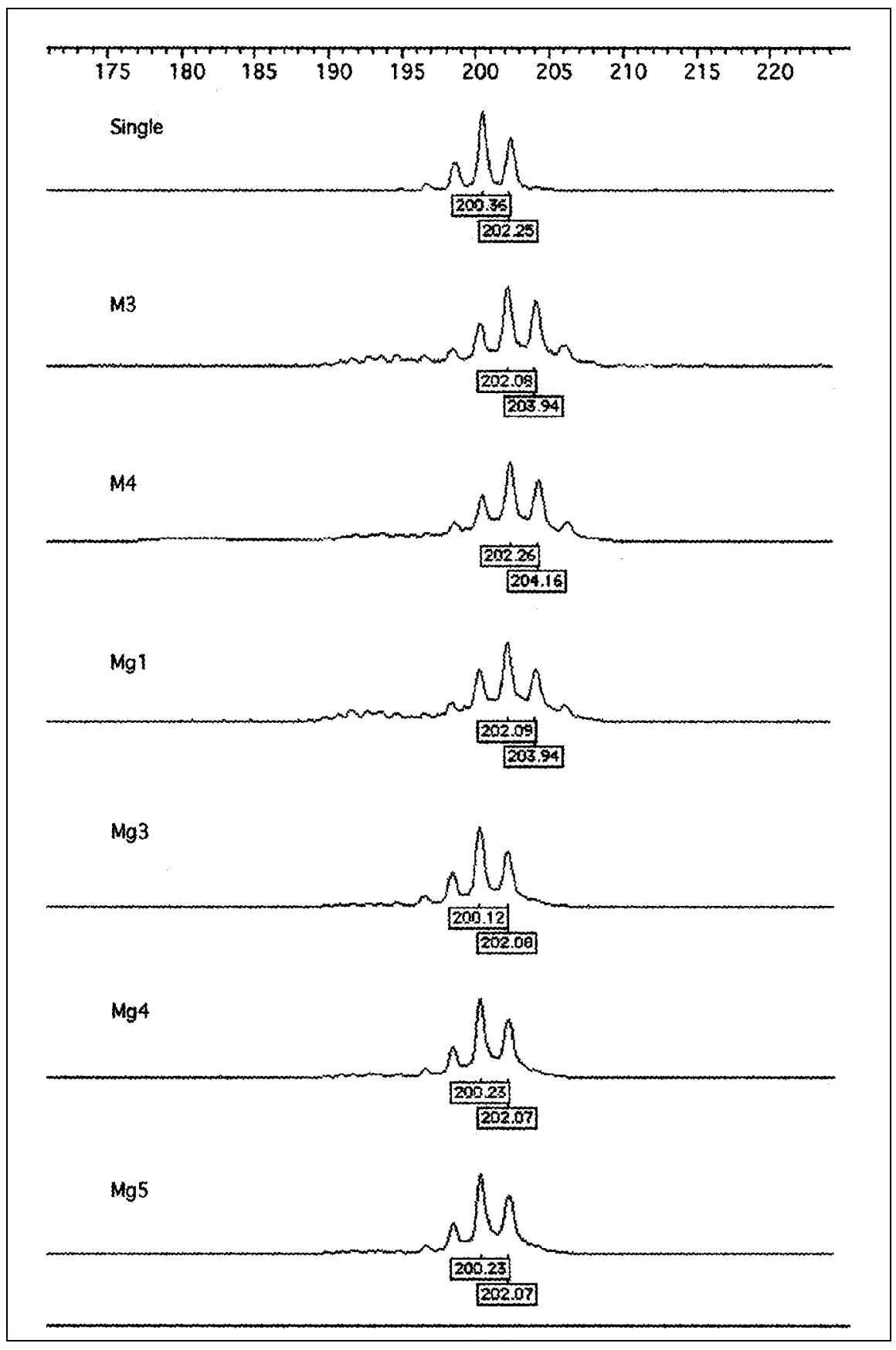

different dye labels, we combined four markers, D1S213, D1S238, D1S468 and D1S484, to perform multiplex PCR (CEPH 1347-02 and p1-p15). Again, the marker D1S468 consistently yielded the 2-bp shift, while the fragment sizes obtained from multiplex and singleplex reactions agreed closely with each other for the remaining three markers. For example, for the marker D1S484, the difference in fragment (the 4-marker set) for the 16 individuals

lengths between multiplex and singleplex ranges from $0.00-0.41 \mathrm{bp}$ with a mean of $0.21 \mathrm{bp}$.

Many factors may influence the results of multiplex PCR $(1,8,9)$. A series of experiments were conducted to explore the conditions that may have led to the 2-bp shift for the marker D1S468. For the multiplex PCR, the conditions were changed one at a time as follows: the quantity of AmpliTaq Gold DNA polymerase was changed from 5 to $3 \mathrm{U}$, the final extension time was changed from 30 to $45 \mathrm{~min}$, and the concentration of DNA was changed from 200 to $100 \mathrm{ng}$. The 2-bp shift consistently occurred in these modified conditions for the marker D1S468. Thus, the factors modified above did not seem to explain the 2-bp shift.

We then performed singleplex PCR for 16 DNA samples (CEPH 1347-02 and p1-p15) with only one marker, D1S468, but under the reagent concentration and thermal cycling conditions for the multiplex PCR. The resultant fragment sizes agreed with those obtained for D1S468 (Figure 1) under the singleplex PCR conditions specified in the Materials and Methods section. Therefore, the different PCR protocols for the multiplex and singleplex reactions do not seem to be underlying the 2-bp shift.

Since D1S468 and D1S484 were common to both sets of multiplex conditions, we tested the hypothesis that interactions between these two markers

Figure 1. Different primer combinations that produce different fragment sizes for the marker D1S468 in the same individual (p4). The top electrophoretogram shows the result for the singleplex PCR under the protocol for singleplex PCR. M3 is a 3-primer-set multiplex PCR using D1S2667, D1S468 and D1S484. M4 is a 4-primerset multiplex PCR using D1S213, D1S238, D1S468 and D1S484. Mg1 is a 2-primer-set multiplex PCR using D1S468 and D1S484. Mg3 is a 4primer-set multiplex PCR using D1S213, D1S238, D1S2726 and D1S468. Mg4 is a 2-primer-set multiplex PCR using D1S2667 and D1S468. Mg5 is one primer D1S468 PCR under the protocol for multiplex PCR. In Figure 1, there are generally three apparent peaks in every condition (single, M3, M4, Mg1, Mg3, Mg4 and Mg5). The first peak in every condition is the lowest one and is apparently a stutter product. Therefore, only the highest two peaks are compared, and the comparison clearly reveals the 2-bp shift for every allele of the individual. 
might explain the 2-bp shift. For eight DNA samples (CEPH 1347-02 and p1-p7), we used the marker D1S2726 (Ned) to replace D1S484 in the 4-marker-set multiplex PCR. We found no shift for every marker including D1S468 (Figure 1). The fragment size difference for D1S468 between multiplex and singleplex reactions ranges from $0-0.43$ bp with a mean of $0.12 \mathrm{bp}$. This is consistent with our hypothesis because the interaction between D1S468 and D1S484 is absent. We then used two primer pairs, D1S468 and D1S484, to perform multiplex PCR in the multiplex conditions. We termed this a 2-markerset multiplex PCR. There was no PCR product for D1S484; however, for D1S468, there were different results for different individuals.

For the eight individuals, the 2-bp shift occurred in five samples, and no shift occurred for two samples (Table 2 ). For one individual (p1), an extra fragment resulting from singleplex PCR occurred in the 2-marker-set multiplex PCR (Figure 2). A repeated experiment yielded similar results. The lack of the PCR product for D1S484 is most likely caused by an interaction between the primers for D1S468 and D1S484 in the absence of other markers. This interaction may be dampened by the presence of other marker primers in the 3- and 4-marker-set multiplex PCR so that the PCR product of D1S484 may be obtained. However, the exact mechanism may be complex and is yet to be explored in further studies. Replacing D1S484 with D1S2667 (Hex), multiplex PCR was repeated and no shift occurred. Therefore, the interaction between the primers D1S468 and D1S484 is essential (although sometimes may not be sufficient) to generate the 2-bp shift.

Unless otherwise specified, we made use of equimolar amounts of primers for different markers in multiplex PCR. To examine the effects of relative primer concentrations on our findings, we performed a further experiment in three individuals (p1, p4 and p6) using the following sets of concentrations for primers D1S468 and D1S484, respectively: (i) $0.264 \mu \mathrm{M}$ and $0.066 \mu \mathrm{M}$; (ii) $0.22 \mu \mathrm{M}$ and 0.11 $\mu \mathrm{M}$; (iii) $0.17 \mu \mathrm{M}$ and $0.17 \mu \mathrm{M}$; (iv) $0.11 \mu \mathrm{M}$ and $0.22 \mu \mathrm{M}$; and (v) 0.066 $\mu \mathrm{M}$ and $0.264 \mu \mathrm{M}$.

Three samples, p1, p4 and p6, were chosen because in the 2-primer-set multiplex PCR with equimolar primers, a partial shift, a 2-bp-shift and no shift occurred, respectively (Table 2). We found that the shift did not occur in the concentration set 1 and always occurred in concentration sets 3 and 4 . No product occurred in concentration set 5 .
In concentration set 2 , the shift occurred in two individuals, $\mathrm{p} 1$ and $\mathrm{p} 4$, and did not occur in one individual, p6. Therefore, the relative concentrations of the primers seem to play a significant role in the occurrence of the 2-bp shift. Appropriate choice of the relative concentration of primer sets may avoid the occurrence of the 2-bp shift.

An additional 4-marker-set (D1S- 


\section{Short Technical Reports}

Table 2. Comparison of the Fragment Sizes of the STR D1S468 between 2-primer-Set Multiplex PCR (D1S468 and D1S484) and Singleplex PCR (D1S468)

\begin{tabular}{|c|c|c|c|c|c|c|c|c|}
\hline ID & CEPH & p1 & p2 & p3 & p4 & p5 & p6 & p7 \\
\hline \multicolumn{9}{|c|}{ 1347-02 } \\
\hline \multirow[t]{2}{*}{ Multiplex } & 194.48 & 205.89 & 207.75 & 207.84 & 202.08 & 203.95 & 200.12 & 205.77 \\
\hline & 203.95 & 207.81 & & & 203.94 & 207.69 & 205.78 & 207.63 \\
\hline \multirow[t]{2}{*}{ Singleplex } & 192.59 & 206.09 & 205.95 & 206.25 & 200.00 & 202.20 & 200.00 & 206.05 \\
\hline & 202.00 & & & 201.85 & 205.79 & 205.42 & 207.91 & \\
\hline Type & 2-bp shift & $\begin{array}{c}\text { Partial } \\
\text { shift }\end{array}$ & 2-bp shift & 2-bp shift & 2-bp shift & 2-bp shift & No shift & No shift \\
\hline \multicolumn{9}{|c|}{$\begin{array}{l}\text { p1-p7 represent different DNA samples obtained from the subjects of a large human genetic study (5). CEPH DNA was ob- } \\
\text { tained from PE Biosystems. In the experiments for this table, equimolar amounts of primers for D1S484 and D1S468 were } \\
\text { employed. A 2-bp shift is defined as the difference between the fragment lengths of multiplex and singleplex reactions greater } \\
\text { than } 1.6 \text { bp but less than } 2.4 \text { bp for each of the alleles (one allele for homozygotes and two alleles for heterozygotes) of a } \\
\text { DNA sample. Partial shift is defined as an extra fragment occurring relative to singleplex PCR so that a homozygote appears } \\
\text { to be heterozygous with an extra fragment of approximately } 2 \text { bp longer. No shift is defined as the difference between the } \\
\text { fragment lengths of multiplex and singleplex reactions within } 0-0.50 \text { bp. }\end{array}$} \\
\hline
\end{tabular}

213, D1S238, D1S468 and D1S484) and a 3-marker-set (D1S2667, D1S468 and D1S484) multiplex reactions were performed in 87 DNA samples (p16p96 and c1-c6). The 2-bp shift was observed in 82 of these individuals (p16-p96 and c5 and c6) for both sets of multiplex PCR. For two individuals (c1 and c4), the 2-bp shift did not occur in the 3-marker-set multiplex PCR, but obviously occurred in the 4-marker-set multiplex PCR. Also, no shift occurred in two individuals (c2 and c3) in both sets of multiplex PCR. The occurrence rate of the 2-bp shift for D1S468 is $100 / 103$ in the 4-marker-set multiplex PCR, 98/103 in the 3-marker-set multiplex PCR and 6/14 for the 2-marker-set

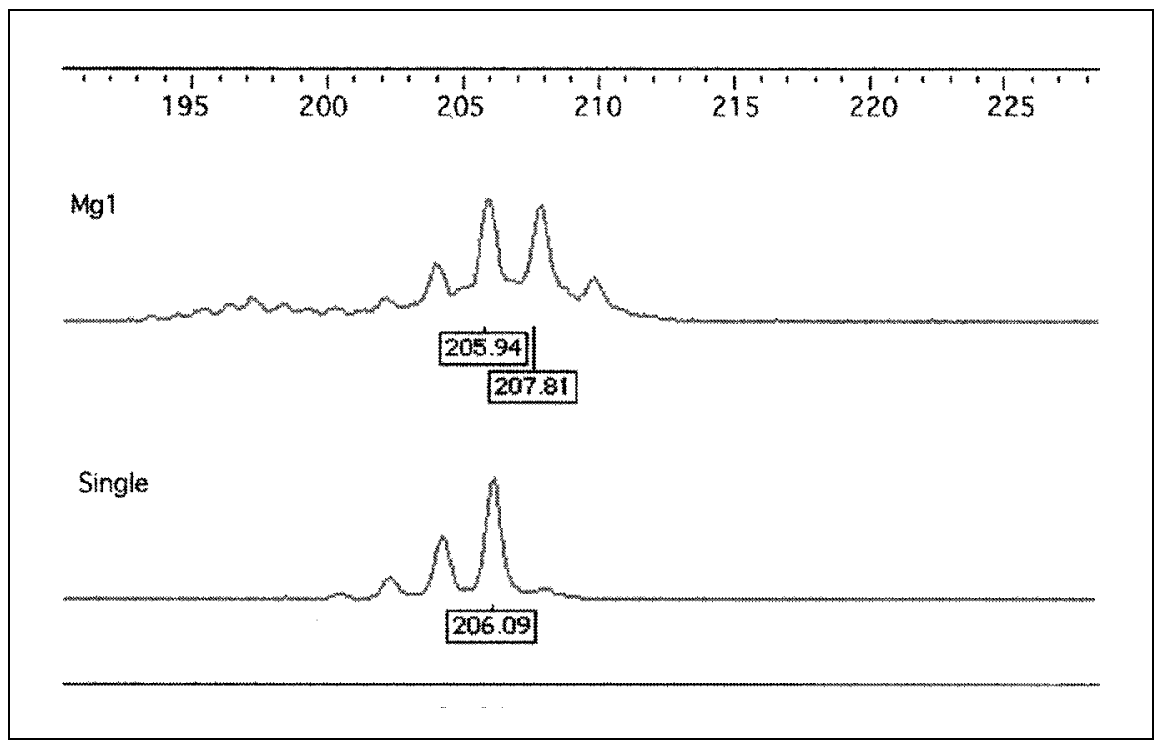

Figure 2. Partial shift for the individual (p1) in a 2-primer-set multiplex PCR. The top electrophoretogram shows that fragment length generated from the 2-primer-set multiplex PCR using D1S468 are 205.94 and 207.81, respectively. The fragment length from the singleplex PCR is 206.09 for the marker D1S468. 


\section{Short Technical Reports}

multiplex PCR (with D1S468 and D1S484). Therefore, the occurrence rate of the 2-bp shift is influenced by the presence or absence of other primers. This suggests to us that the primer-primer interaction that results from other markers may also play a role (although not a fundamental one) in the occurrence of the 2-bp shift.

Because the concentration of $\mathrm{MgCl}_{2}$ is important for the production and specificity of singleplex and multiplex PCR (9), we performed singleplex PCR for D1S468 and for the 2-, 3- and 4-marker-set multiplex PCR under different $\mathrm{MgCl}_{2}$ concentrations. These concentrations ranged from $1-4 \mathrm{mM}$. We found that there was no PCR product for all the reactions less than or equal to $1 \mathrm{mM} \mathrm{MgCl} 2$. For the singleplex PCR, the fragment sizes obtained from the different $\mathrm{MgCl}_{2}$ concentrations (ranging from 1.5-4 mM) were the same. However, for the multiplex PCR when the concentration of $\mathrm{MgCl}_{2}$ is equal to or less than $2 \mathrm{mM}$, the 2-bp shift occurred. When the $\mathrm{MgCl}_{2}$ concentration is 1.5 $\mathrm{mM}$, the 2-bp shift did not occur. Therefore, the concentration of $\mathrm{MgCl}_{2}$ is also critical for the occurrence of the 2-bp shift. Optimization of multiplex PCR conditions, particularly the concentration of $\mathrm{MgCl}_{2}$, may reduce or eliminate the occurrence of the 2-bp shift.

The thermal cycling condition we used for singleplex PCR was recommended by PE Biosystems for the linkage mapping software (20). Although it remains a hypothesis to be tested, it seems unlikely that the shift is caused by the pairing of primers from different primer pairs in multiplex PCR.

The forward and reverse primers are usually shipped and mixed in one tube for each marker in the linkage mapping software. We obtained the forward and reverse primers separately for D1S468 and D1S484 and performed the follow- ing experiments by singleplex PCR using six DNA samples to examine the possibility that combinations of primers from D1S468 and D1S484 may amplify a new and nontargeted STR locus. The six DNA samples were from the CEPH DNA and p1-p5. The following primer combination was used: forward primer for D1S484 and reverse primer for D1S468; forward primer for D1S468 and reverse primer for D1S484; forward primer for D1S484 and unlabeled forward primer for D1S468; and forward primer for D1S468 and unlabeled forward primer for D1S468. Unless otherwise specified, all the forward primers are fluorescently labeled.

In addition, the following singleplex PCR experiments were performed as control reactions with the following primer combinations: forward primer for D1S468 and reverse primer for D1S 468 and forward primer for D1S484 
and reverse primer for D1S484. Except for the control reactions, there is no PCR product in the other four singleplex reactions. Although there are 10 possible combinations of primers for D1S468 and D1S484, we only tested six of the 10 as indicated. The other four combinations are not meaningful for testing (e.g., D1S484 forward primer and D1S484 forward primer) or cannot be tested because of the limited access to labeled/unlabeled unpaired primers (e.g., D1S484 reverse and D1S468 reverse). The primer combination of D1S484 forward and D1S484 forward cannot possibly have amplified a new STR locus. Otherwise, the new locus would have been detected as an extra product in the control singleplex PCR experiment for D1S484. Because the 2-bp shift was detected as fluorescently labeled products in the multiplex PCR, the shift could not have been generated by combinations of unlabeled reverse primers. Therefore, our experimental results together with the previous genetics argument clearly indicate it was unlikely that primerprimer interaction might have amplified a new and nontargeted STR locus in the genome. Extreme primer-primer interaction may lead to pairing of primers from different markers so that a new STR locus may be amplified.

Many studies have reported that primer-primer interaction will result in little or no PCR product for some markers in multiplex PCR (9). To the best of our knowledge, this is the first report of an extreme form of primerprimer interaction that yields fragment length difference between multiplex and singleplex reactions. Experiments for many of the results on the 2-bp shift were repeated at least once, and all the repeated experiments revealed the robustness of our findings. For those DNA samples in which the 2-bp shift did not occur, repeated experiments were also conducted and all the nonshifts were confirmed.

Therefore, it appears that DNA samples may be one factor in determining whether or not the 2-bp shift occurs, although the specific mechanism is not clear. We examined the effects of DNA concentration with the CEPH DNA by varying the amount of DNA from $75 \mathrm{ng}$ up to $1 \mu \mathrm{g}$ in the $50-\mu \mathrm{L}$ reaction in 2 -
(D1S468 and D1S484), 3- (D1S468, D1S484 and D1S2667) and 4-marker (D1S468, D1S484, D1S213 and D1S238) multiplex PCR. The 2-bp shift consistently occurred.

In light of the increasingly rapid application of multiplex PCR $(1,6,7,10$, $12,14,15,17-19,21)$ and recent recommendations from PE Biosystems to perform multiplex PCR in whole genome scans, our findings have significant implications. For example, whole genome linkage studies are often costly, consume time and labor and frequently involve genotyping for hundreds of STR loci for hundreds of study subjects (especially for complex diseases). Multiplex PCR has been used in whole linkage studies (11) to reduce the time, labor and reagent expenses. Because multiplex PCR will fail to amplify some markers for some individuals (11), it is more economical and common practice to use singleplex PCR as a supplement to multiplex PCR for markers in those for whom multiplex PCR fails to amplify. However, if the fragment lengths differ in multiplex and singleplex reactions in units of repeat size of an STR (here, it is two base pairs for the dinucleotide STR D1S468), genotyping data will be different for multiplex and singleplex reactions and induce an extra source of genotyping error.

As demonstrated earlier relative to the singleplex PCR, multiplex PCR will have fragment length difference for some individuals but not for others. This will increase genotyping errors even when using multiplex PCR alone. The fragment length difference will not be known without specific studies such as those we conducted. If the potential difference is ignored, the practice of using singleplex PCR to supplement multiplex PCR will introduce an extra source of genotyping error. Even worse, if the fragment length difference occurs for some samples and not for others (as was the case here), the difference cannot be adjusted for multiplex and singleplex reactions even if we know it may occur. Similar problems exist for making use of multiplex PCR in DNA typing. Therefore, caution should be taken to ensure the absence of potential primer-primer interactions in the extreme form of fragment length 
change in multiplex PCR relative to singleplex PCR.

In the presence of primer-primer interactions of fragment length change, several solutions to the problem may be tried-optimization of the concentration of $\mathrm{MgCl}_{2}$, selection of relative concentration of primer pairs, design of different primers for one of the other loci involved in the interaction or extending by several bases the 3 -end of the primers of one locus or simply trying to avoid the use of multiplex PCR for those markers that interact in such an extreme form. However, before a strategy is devised, those markers with interacting primers should be identified first.

\section{REFERENCES}

1.Anonymous. 1992. Diagnosis of Duchenne and Becker muscular dystrophies by polymerase chain reaction. A multicenter study. JAMA 267:2609-2615.

2.Brownstein, M.J., J.D. Carpten and J.R. Smith. 1996. Modulation of non-templated nucleotide addition by Taq DNA polymerase: primer modifications that facilitate genotyping. BioTechniques 20:1004-1010.

3.Burgart, L.J., R.A. Robinson, M.J. Heller, W.W. Wilke, O.K. Iakoubova and J.C. Cheville. 1992. Multiplex polymerase chain reaction. Mod. Pathol. 5:320-323.

4.Chamberlain, J.S., R.A. Gibbs, J.E. Ranier, P.N. Nguyen and C.T. Caskey. 1988. Deletion screening of the Duchenne muscular dystrophy locus via multiplex DNA amplification. Nucleic Acids Res. 16:11141-11156.

5.Deng, H.-W., W.-M. Chen, T. Conway, Y. Zhou, K.M. Davies, M.R. Stegman, H. Deng and R.R. Recker. Determination of BMD at hip and spine by genetic and life-style factors. Genet. Epidemiol. (In Press.)

6.Edwards, A., A. Civitello, H.A. Hammond and C.T. Caskey. 1991. DNA typing and genetic mapping with trimeric and tetrameric tandem repeats. Am. J. Hum. Genet. 49:746756.

7.Entrala, C., M. Lorente, J.A. Lorente, J.C. Alvarez, T. Moretti, B. Budowle and E. Villanueva. 1998. Fluorescent multiplex analysis of nine STR loci: Spanish population data. Forensic Sci. Int. 98:179-183.

8.Gyapay, G., J. Morissette, A. Vignal, C. Dib, C. Fizames, P. Millasseau, S. Marc, G. Bernardi et al. 1994. The 1993-94 Généthon human genetic linkage map. Nat. Genet. 7:246-339.

9.Henegariu, O., N.A. Heerema, S.R. Dlouhy, G.H. Vance and P.H. Vogt. 1997. Multiplex PCR: critical parameters and step-by-step protocol. BioTechniques 23:504-511.

10.Henegariu, O., P. Hirschmann, K. Kilian, S. Kirsch, C. Lengauer, R. Maiwald, K. Mielke and P. Vogt. 1994. Rapid screening of the $\mathrm{Y}$ chromosome in idiopathic sterile men, diagnostic for deletions in AZE, a genetic Y factor expressed during spermtogenesis. Andrologia 26:97-106.

11.Johnson, M.L., G. Gong, W. Kimberling, S.M. Recker, D.B. Kimmel and R.R. Recker. 1997. Linkage of a gene causing high bone mass to human chromosome 11 (11q12-13). Am. J. Hum. Genet. 60:1326-1332.

12.Kimpton, C.P., P. Gill, A. Walton, A. Urquhart, E.S. Millican and M. Adams. 1993. Automated DNA profiling employing multiplex amplification of short tandem repeat loci. PCR Methods Appl. 3:13-22.

13.Kupferschmid, T.D., T. Calicchio and B. Budowle. 1999. Maine Caucasian population DNA database using twelve short tandem repeat loci. J. Forensic Sci. 44:392-395.

14.Lee, D.H., J.S. Han, W.G. Lee, S.W. Lee and H.M. Rho. 1998. Quadruplex amplification of polymorphic STR loci in a Korean population. Int. J. Legal Med. 111:320-322.

15.Liew, C.T., H.M. Li, K.W. Lo, C.K. Leow, W.Y. Lau, L.Y. Hin, B.K. Lim, P.B.S. Lai et al. 1999. Frequent allelic loss on chromosome 9 in hepatocellular carcinoma. Int. J. Cancer 81:319-324.

16.Pertl, B., U. Weitgasser, S. Kopp, P.M. Kroisel, J. Sherlock and M. Adinolfi. 1996. Rapid detection of trisomies 21 and 18 and sexing by quantitative fluorescent multiplex PCR. Hum. Genet. 98:55-59.

17.Ponce, M.R., P. Robles and J.L. Micol. 1999. High-throughput genetic mapping in
Arabidopsis thaliana. Mol. Gen. Genet. 261: 408-415.

18.Richards, R.I., K. Holman, Y. Shen, H. Kozman, H. Harley, D. Brook and D. Shaw. 1991. Human glandular kallikrein genes: genetic and physical mapping of the KLK1 locus using a highly polymorphic microsatellite PCR marker. Genomics 1 1:77-82.

19.Shuber, A.P., J. Skoletsky, R. Stern and B.L. Handelin. 1993. Efficient 12-mutation testing in the CFTR gene: a general model for complex mutation analysis. Hum. Mol. Genet. 2:153-158.

20.The Perkin-EImer Corporation. 1997. ABI PRISM $^{\mathrm{TM}}$ Linkage Mapping Set Version 2 User's Manual.

21.Wang, X. and M.I. Khan. 1999. A multiplex PCR for Massachusetts and Arkansas serotypes of infectious bronchitis virus. Mol. Cell Probes 13:1-7.

This study was supported by grants from National Institutes of Health, Health Future Foundation and HuNan Normal University, and by graduate student tuition waivers to Y.Z. and J.L. from Creighton University. We are very grateful to the three anonymous reviewers for their helpful and careful comments that greatly helped to improve this paper. Address correspondence to Dr. Hong-Wen Deng, Osteoporosis Research Center, Creighton University, 601 N. 30th St., Omaha, NE 68131, USA. e-mail: deng@creighton.edu

Received 13 September 1999; accepted 10 April 2000.
H.-W. Deng1,2, Y. Zhou', R.R. Recker ${ }^{1}$, M.L. Johnson ${ }^{1}$ and $\mathbf{J} . \mathbf{L i}^{1}$
${ }^{1}$ Creighton University
Omaha, NE, USA
${ }^{2}$ Hunan Normal University Hunan, P.R. China 